\title{
Formulating an integrated intervention programme: reshaping the brain-behaviour functioning of children in conflict with law in india
}

\begin{abstract}
Juvenile delinquency is a serious social concern, characterized by disturbance in executive functions, cognitive emotion regulation and aggression. The term 'children in conflict with the law' refers to any individual below the age of 16years, who has come in contact with the justice system as a result of committing an illegal activity or being suspected of committing an illegal activity. It can be easily understood that the Children in Conflict with Law require rehabilitative measures while they are spending their formative years of life in Juvenile Justice Homes. Rehabilitation has particularly been the focus of corrections programs for Children in Conflict with Law. Research in different parts of the world has focused on various facets of psychotherapeutic intervention like Behaviour Therapy, Contingency management programme, Family Therapy, Music therapy etc. that have been effectively applied in separate formats on these children. It is often found that while implementing psychotherapeutic intervention programmes in practice, these have often not reached up to the extent of their wholistic betterment. This is also true in the Indian context where published research in this particular domain is sparse. To reach the aim of reducing or preventing future criminal behaviour, it is much necessary to strengthen and integrate the appropriate execution of existing psychotherapeutic intervention programmes for delinquency prevention. This paper aims to delineate the conceptual formulation of an Integrated Intervention Programme which is aimed at providing rehabilitation for Children in Conflict with Law. It includes Psycho-education, Music Therapy, Psychodrama and finally Cognitive Behaviour Therapy as well as Cognitive Retraining to enhance positivity, aid in self expression and better emotional regulation and promote adaptive executive functioning. Starting with the Group Therapy mode, the Programme will gradually move towards an individual format to deal specifically with the individualistic needs of each child.
\end{abstract}

Keywords: children in conflict with law, juvenile delinquency, integrated intervention programme, psycho-education, music therapy, psychodrama, cognitive behaviour therapy
Volume 6 Issue 7 - 2016

\author{
Priyanka Podder,' Sanjukta Das, ${ }^{2}$ Vaya SL, ${ }^{3}$ \\ Sarathi Chatterjee ${ }^{4}$ \\ 'Clinical Psychologist, University of Calcutta, Indi \\ ${ }^{2}$ Department of Psychology, University of Calcutta, India \\ ${ }^{3}$ Director (Research \& Development), Raksha Shakti University, \\ India \\ ${ }^{4}$ Hindustani Classical Vocalist, India
}

\begin{abstract}
Correspondence: Sanjukta Das, Professor and Head of Department of Psychology, University College of Science, Technology and Agriculture, University of Calcutta, 92, A.P.C. Road, Kolkata, Pin no. -700009, West Bengal, India, Tel 91 9433103267,Email sanjuktapsych@yahoo.com
\end{abstract}

Received: November 25, 2016 | Published: December 21, 2016

\section{Introduction}

In this modern era, the lifestyle trajectories are becoming much varied and less predictable. The most maladaptive and detrimental outcomes of these are probably borne by the children and youth of the society. Juvenile delinquency is perhaps the most prominent amongst them. Children in Conflict with Law are children who participate in illegal activities that are in line with criminal acts as per the Indian Penal Code.

As they enter the Juvenile Justice Homes, these children do bring with them a number of serious concerns that needs to be taken care of in order to facilitate their consequent reformation. These concerns are mostly related to that of substance abuse, medical problems, poor academic performance, emotional disturbances, poor interpersonal relationships and a history of abuse which can be verbal, emotional, physical or sexual. This is more often true for girls who make up quite a high percentage of children staying in the Juvenile Justice Homes. To free these children of such problems, it is essential to take into consideration their age and developmental stage and consequently, pave the way for comprehensive assessment, medical and psychological intervention programmes and provide necessary support services as deemed suitable.

\section{Discussion}

To undertake the task of formulating an appropriate psychotherapeutic intervention programme, it is of utmost importance to have a detailed knowledge of the causal mechanisms underlying the construct of juvenile delinquency. Both neurobiological and psychological underpinnings coexist in the etiological framework of Juvenile delinquency. Neurobiological deficits including poor executive functioning and maladaptive functioning of the cortical and sub cortical regions responsible for emotion regulation, hyperactivity and risk taking behaviour have been found to play a major role here. Early negative experiences, including physical and sexual abuse, rejection and neglect from society, broken homes, impoverished financial status, domestic violence etc. are often faced by Children in Conflict with Law. ${ }^{1-4}$ This installs in them frustration, feelings of insecurity along with a host of other disruptive emotional processes that eventually pave the way for impulsivity, anger outbursts, hostility and a tendency to violate the rights of others. This culminates into the illegal activities undertaken by them.

It is very essential to identify various early negative experiences faced by these children, understand the various deficits in executive functions, which include difficulties in flexibility of thinking, abstract thinking, response inhibition, adequate problem solving, foresight and planning, control impulses effectively and concept formation skills, as well as the various psychosocial factors that are usually inherently associated or linked significantly with these constructs. This can lead to an overall understanding of the executive dysfunction, cognitive emotional dysregulation and hostility prevalent among Children in Conflict with Law. 
Neuropsychological vulnerabilities are much relevant in Juvenile delinquency. ${ }^{5,6}$ Studies have shown that verbal learning and verbal reasoning ability can predict delinquency but not nonverbal domains. ${ }^{7,8}$ Studies report decreased verbal ability of antisocial. ${ }^{9,10}$ Children with executive or verbal deficits might have difficulty in foreseeing behavioural consequences and have poor empathy ${ }^{11}$ which leads to delinquency. Delinquency is marked by emotional and behavioural dysregulation. In this context, cognitive impairment related to the executive functions of working memory and responses to stimuli are implicated in the development and maintenance of aggression and violence. ${ }^{12}$ Perseveration to previous sources of rewards is noted among Children in Conflict with Law, even if it results in punishment. ${ }^{13}$ Neurobiological markers of fearlessness are often associated with delinquent behaviour. ${ }^{14}$

According to ${ }^{15}$ several studies on executive functions of Children in Conflict with Law show deficit in attention modulation, response inhibition, verbal fluency, planning and decision making, selective attention and sequencing of motor behaviour. According to, ${ }^{16}$ verbal abstract reasoning and auditory verbal memory are important constructs behind self-control. These are found to be impaired in Children in Conflict with Law. Children with frontal lobe deficit are more likely to how aggression and poor social behaviour. According to,${ }^{17}$ neuropsychological deficits linked to self-control are strongly associated with delinquency and other psychopathological conditions. ${ }^{18,19}$ These are mostly prevalent among children with both Attention Deficit Hyperactivity Disorder and Conduct Disorder ${ }^{20}$ and are more in males than females.

In terms of brain connections underlying impulsivity, the orbitofrontal cortex and the basolateral nucleus of the Amygdala provide major nodes in the limbic cortico-striatal loop and link with Nucleus Accumbens. Nucleus Accumbens lesions increase impulsivity. This is high among Children in Conflict with Law. ${ }^{21,22}$ Impulsivity is highly related to substance abuse ${ }^{23}$ and violence..$^{24,25}$

Poor executive function, cognitive emotion dysregulation and maladaptive social behaviour associated with delinquency are required to be intervened for rehabilitation and prevention programme. Neurobiological correlates of delinquent behaviour needs to be addressed through different aspects of executive functioning, cognitive emotion regulation and other manifested maladaptive behaviour pattern of the children. The cortico-limbic and corticothalamic areas of the brain are related with manifested behaviour of Children in Conflict with Law. Intervention for these Children in Conflict with Law must be planned considering these pathways, through the activities which reciprocally counter these maladaptive occurrences.

Psychology has, since long, taken measures to curb down Juvenile delinquency, by facilitating its prevention and rehabilitation. To aim for treatment and prevention of Juvenile delinquency, worldwide researchers have implemented different modes of intervention, some of which have proven to be highly efficacious with this group of children and adolescents. Research in this domain have provided various evidence based strategies to deal with Juvenile delinquency, which highly focuses on approaches involving Family Therapy, ${ }^{26-28}$ skills training and developing interpersonal relationships ${ }^{29-31}$ of these children. However, there are mixed reviews regarding the efficacy of these intervention programmes. ${ }^{32}$

A critical review of the theoretical and outcome studies on Family Therapy with Children in Conflict with Law was done by. ${ }^{33}$ They found that Family Therapy is highly efficacious in dealing with Children in
Conflict with Law. Functional Family Therapy was developed in the 1960s and 70s to work specifically with delinquent youths. ${ }^{34}$ Stuart, in 1970s, has carried out series of research in this domain. Research on Children in Conflict with Law using Functional Family Therapy has demonstrated it's usefulness in reducing recidivism and facilitating adaptive behaviours. ${ }^{35-40}$

Group Therapy has also been carried out in various groups of Children in Conflict with Law. ${ }^{41,42}$ Social skills training modules are quite effective as well. ${ }^{43-46}$ Some studies have focused on the application of certain Behaviour Therapy techniques. ${ }^{47-49}$

Besides this, it needs to be mentioned here that ${ }^{50}$ have focused on a comparative analysis of treatment types in institutionalized and noninstitutionalized Children in Conflict with Law. The different modes of therapeutic approaches found to be effective among institutionalized Children in Conflict with Law are interpersonal skills training, ${ }^{51-53}$ family treatment,,$^{54,55}$ behavioural programmes ${ }^{56-58}$ and community residential programmes. ${ }^{59-61}$

Some studies have focused on using Music Therapy in the intervention of Children in Conflict with Law. A meta-analytic study was undertaken to determine the effects of Music Therapy on children and adolescents with psychopathology and found it to be efficacious. ${ }^{62}$ Beneficial therapeutic potential of rap music intervention was found in group work with Children in Conflict with Law. ${ }^{63}$ Some have worked on the role of objective and concrete feedback in self-concept treatment of Children in Conflict with Law using Music Therapy. ${ }^{64}$ He found that specific changes occur in this group of children who perceive themselves as having lesser rebellious and distrustful traits. Some researchers have compared the behavioral effects of active, rhythm-based Group Music Therapy and that of passive, listeningbased Group Music Therapy on preadolescents with emotional, learning, and behavioral disorders. ${ }^{65}$ It was found that Group Music Therapy can facilitate the process of self-expression and provide a channel for transforming negative emotions into the experience of creativity and self-mastery. A case study of a $15 y$ year old boy was put forward, identified as Child in Conflict with Law, who was treated effectively using music instruments as a means of rehabilitation. ${ }^{66}$

Existing international literature indicates that executive dysfunction and cognitive emotion dysregulation are key components of Juvenile delinquency. Different therapeutic modes, like Family Therapy, Behavioural Therapy, Music Therapy, skills training etc. have been found to be effective. In the Indian context, our clinical experience suggests that as these children often hail from homeless background, broken homes and dysfunctional families, hence, it is difficult to use Family Therapy techniques for intervention in the current socio-cultural context. Intervention in group situation has also been found to be useful. In the Indian context, review of existing literature shows that some researchers have focused on Juvenile delinquency. A study was conducted on factors underlying Juvenile delinquency ${ }^{67}$ Poduthase $\mathrm{H}^{68}$ have studied the parent - adolescent relationships among Children in Conflict with Law in Kerala. Various other researchers have conducted studies on Children in Conflict with Law. ${ }^{69-71}$ However, no studies were found that did focus on the treatment and rehabilitation of Children in Conflict with Law in India.

In the Indian context, there is great scarcity of research highlighting the area of the treatment and rehabilitation of Children in Conflict with Law. It is a well known fact that India is going through a gradual escalation in the severity and frequency of crimes taking place. This has led to frequent amendments and associated changes being incorporated in the legal codes and implemented accordingly. 
However, the prevention and rehabilitation programmes with special emphasis on Children in Conflict with Law, who can further themselves into hardbound, chronic criminal careers, have seen no limelight. Moreover, the evidence - based approaches that swiftly prove successful in other countries are hardly possible in the Indian context because of the cultural diversity and other culture specific factors that are inherent in the Indians. There is a lack of adequate social support systems that can provide a cradle to rehabilitate these children and prevent recidivism. Thus, it is essential that one should frame an integrated intervention programme that address the deficits underlying Juvenile delinquency and can operate in harmony with the available structure in which these children dwell and also make use of the extensive Indian traditional socio-cultural resources to curb Juvenile delinquency.

Although the exponents of Indian classical music have emphasized the efficacy of its use in treatment and rehabilitation purposes ${ }^{72}$ there is a scarcity of published research in this domain, ${ }^{73}$ especially focused on treatment of Children in Conflict with Law. ${ }^{74}$ Probed into the relationship between emotions and classical music, using electroencephalogram signals. They concluded that there occurs more positive effect in the brain after hearing Indian classical music as compared with other forms of music. Thus, it can be used as a tool for inducing positive mental state. ${ }^{75}$ Used Indian classical music in treatment of Depression. ${ }^{76}$ worked in a similar area with Schizophrenia and Depression. ${ }^{77}$ Showed significantly better improvement in patients with Depression while using music for their treatment rather than those who received only psychotropic medications. ${ }^{78}$ and ${ }^{79}$ have showed efficacy of Music Therapy in treatment of Schizophrenia. ${ }^{80}$ Have found that Music Therapy is useful to enhance self-esteem among academically stressed adolescents.

Review of existing literature suggests that there is a need to conduct an extensive systematic research focusing on intervention to address neurobiological and psychosocial problems of Children in Conflict with Law in the Indian context. Study needs to be conducted specifically focusing on executive dysfunction and cognitive emotion dysregulation associated with Juvenile delinquency. To achieve this, work on intervention programme with this group of children can utilize traditional indigenous resources for better efficacious outcome.

The clinical knowledge and the experiential learnings of the authors have also been taken into account, during the conceptualization of the psychotherapeutic intervention programme besides the literature review. Findings obtained from prior research works have led to certain fundamental understanding regarding the sufferings and needs of this group of individuals, which pointed out the dire necessity of formulating a standardised Integrated Intervention Programme to aim for the prevention of further criminal conduct and rehabilitation. While working with children diagnosed as having Conduct disorders as well as those who engage in risk - taking maladaptive behaviours that can go up to the level of violating the social rules or the rights of others, it was realized that conventional mode of therapeutic approaches does not have a lasting impact on these children. They are unable to express themselves adequately and are often guarded or only express themselves through aggressive means. In this context, at first, it has been felt necessary to make them aware of their current status for their better understanding of their strengths and difficulties. This can be followed by facilitating a positive mental state and emotional expression; which is to be followed by aiding in adequate executive functioning.

To bring about the interface mentioned above, use of music and other psychotherapeutic techniques like Psychoeducation, Psychodrama, Cognitive Behavioural Therapy as well as both individualistic and group mode of therapy can act as an essential component that can bridge the gap between the constructs of Juvenile delinquency and formulation of Integrated Intervention Programme using music, via Neuroscience. Music has been used as a psychotherapeutic technique since long in order to address the emotional, social, cognitive and physical needs of Children in Conflict with Law. It provides avenues of communication that can be useful to those who find it difficult to express themselves otherwise.$^{81}$ Research involving music has brought forward the effectiveness of music in enhancing the psychological wellbeing and physiological health. It has been used as a tool for relaxation and catharsis, reduction of stress, to enhance the feeling of positivity, inner strength and to restore peace of mind ${ }^{82}$ It is an accepted notion in the field of Indian classical music that different moods and psychological states may be created by different combinations and compositions of musical notes. The impact of music on the psyche of an individual can influence different psychological processes that can aid in adaptive and harmonious operation of emotions and executive functioning.

Research have shown that exposure to music can excite the cortico-limbic and cortico-thalamic circles that can have a positive impact on the executive functions, attention, memory, motor functions ${ }^{83}$ and emotional regulation. ${ }^{84}$ This can, in turn, facilitate the overall healthy functioning of an individual by alleviating sources of distress and related psychosocial concerns. However, different other Psychotherapeutic approaches like Cognitive Behavioural Therapy can facilitate this process directly and can be used effectively when an individual is motivated enough for seeking such professional therapeutic help. As Children in Conflict with Law are not expected to be motivated enough for seeking such help, this Integrated Intervention Programme starts with those techniques which address these issues indirectly like Music Therapy and Psychodrama. After certain period of time when some changes already would occur, direct individualized psychotherapeutic techniques will be introduced with an expectation of their active involvements in seeking such help. Review of existing literature, thus, shows that music can be used as an effective intervention tool for Children in Conflict with Law to address their associated executive dysfunction and cognitive emotion dysregulation. For this purpose, the vast resource of Indian Classical Music can be utilized which can be used nation-wide, irrespective of different sub-cultures within India.

From the above discussion, it is clear that the neurobiological and psychosocial factors underlying Juvenile delinquency can be intervened by music and certain psychotherapeutic techniques which actually would work via its neurobiological mechanisms. More elaborately it may be said that authentic and systematic training and use of music can produce neurobiological changes e.g., lowering the activity of sympathetic nervous system with a gradually sustainable parasympathetic activation and balanced functioning of Prolactin and Oxytocin; it may empower an individual by achieving better executive function with greater emotional regulation and finally a more relaxed positive state of mind. Thus, areas of the human psyche that works in a maladaptive manner can be modified to function in an adaptive format through the use of music. This can have its positive impact on self regulation, interpersonal relationships and other psychosocial skills to deal with early negative experiences.

An Integrated Intervention Programme have been devised in order to facilitate the rehabilitation of Children in Conflict with Law by modifying the executive dysfunction and cognitive emotional 
dysregulation, which can culminate in reduction of recidivism and prevention of further deliquent behaviours. This programme includes use of music and other psychotherapeutic techniques like Psychoeducation, Psychodrama as well as both individualistic and group mode of therapy. Starting with Group Therapy approaches, it can be furthered on an individual level to deal with maladaptive cognitions and behaviours, using Cognitive Behavioural Therapy, for a wholistic upheaval of these children. The details of the Integrated Intervention Programme are given below.

\section{Details of integrated intervention programme}

The intervention consists of the following modules whereby intervention modules 1-3 can be administered in group situation; and 4th module needs to be implemented individually on the Children in Conflict with Law.

Module 1: Psycho-education: It would focus on -

A. To make them aware of their social and personal current status with an emphasis on its implication towards their future

B. To focus on their strengths which may be appreciated and deficiencies which can be overcome

Module 2: Music Therapy would be used for intervention (in both ways, as active mode and recipient mode) which will serve to -

i. Provide a soothing mental state, stimulating parasympathetic activation and lowering cortical over-arousal;

ii. Enhance a positive state of mind

iii. Facilitate emotional expression and catharsis

iv. Enhance executive functioning

Module 3: Psychodrama - it would be used for social skills training, including training in socially adaptive expression of anger.

Module 4 : Cognitive Behavioural Therapy techniques -

This would be used on an individual level to address maladaptive cognition and behavior further. In this phase, Cognitive Retraining needs to be introduced for further betterment, considering the level of motivation.

\section{Conclusion}

In a document produced by, ${ }^{85}$ it is found that cases of crime have gradually increased over the years. This holds true for Children in Conflict with Law as well. The current scenario of the nation upheld that there exist a large number of children and adolescents who have been identified as Children in Conflict with Law and are institutionalized. To counter this social concern, it is deemed necessary to prepare an appropriate therapeutic intervention programme to prevent the same. In order to bring them back to the mainstream society, it is important to make them productive by utilizing the child and youth resources and facilitate their rehabilitation.

Even though adult criminals receive greater focus in the Indian subcontinent in terms of their rehabilitation, as found from the review of existing literature, there was found no published systematic research emphasising the rehabilitation of Children in Conflict with Law. Review of literature does not show any such published and evidence-based existing effective programme present in the Indian subcontinent. This is why, an Integrated Intervention Programme aiming for prevention and rehabilitation of Juvenile delinquency have been formulated. Children and adolescents are often mouldable and they can be rehabilitated with the aim of modifying their maladaptive thoughts, behaviours and emotions into an adaptive fashion. This can lead to prevention of future crimes and reduction of further social pathology, as it is understandable that individuals who take up criminal activities at an early age are most prone to become chronic and hardened criminals in future. The proposed Integrated Intervention Programme can thus aid in positive societal contribution.

\section{Acknowledgments}

None.

\section{Conflicts of interest}

Author declares there are no conflicts of interest.

\section{Funding}

None.

\section{References}

1. Hoffman JP, Cerbone FG. Stressful Life Events and Delinquency Escalation In Early Adolescence. Criminology. 1999;37(2):343-374.

2. Duke NN, Pettingell SL, McMorris BJ, et al. Adolescent violence perpetration: associations with multiple types of adverse childhood experiences. Paediatrics. 2010;125(4): e778-e786.

3. Li Y. Out-of-home care experience and juvenile delinquency during transition from adolescent to adult (unpublished doctoral dissertation) Iowa State University, United States. 2011

4. Kabiru CW, Elung'ata P, Mojola SA, et al. Adverse life events and delinquent behavior among Kenyan adolescents: a cross-sectional study on the protective role of parental monitoring, religiosity, and selfesteem. Child Adolesc Psychiatry Ment Health. 2014;8:24.

5. Donnellan MB, Trzesniewski KH, Robins RW, et al. Low self-esteem is related to aggression, antisocial behavior, and delinquency. Psychol Sci. $2005 ; 16(4): 328-335$.

6. White JL, Moffitt TE, Caspi A, et al. Measuring impulsivity and examining its relationship to delinquency. J Abnorm Psychol. 1994;103(2):192-205.

7. Elkins IJ, McGue M, Iacono WG. Genetic and environmental influences on parent-son relationships: Evidence for increasing genetic influence during adolescence. Dev Psychol. 1997; 33(2):351-363.

8. Frost LA, Moffitt TE, McGee R. Neuropsychological correlates of psychopathology in an unselected cohort of young adolescents. $J$ Abnorm Psychol . 1989;98(3):307-313.

9. Fergusson DM, Horwood LJ. Early disruptive behavior, IQ, and later school achievement and delinquent behavior. J Abnorm Child Psychol. 1995;23(2):183-199.

10. Benjamin BL, Keith M, Rolf L. Are attention-deficit/hyperactivity disorder and oppositional defiant disorder developmental precursors to conduct disorder? Handbook of Developmental Psychopathology. New York, NY: Plenum Press, USA. 2000. p.431-446.

11. Farrington D. Human Development and Criminal Careers. In: Maguire et al. (Eds.), The Oxford Handbook of Criminology. Oxford: Clarendon Press, USA. 1994.

12. Loeber R, Pardini D. Neurobiology and the development of violence: Common assumptions and controversies. Philos Trans $R$ Soc Lond B Biol Sci. 2008;363(1503):2419-503.

13. Wallace LH, Patchin JW, May JD. Reactions of Victimized Youth: Strain as an Explanation of School Delinquency. Western Criminology Review. 2005;6(1):104-116 
14. Loeber R, Pardini D. Neurobiology and the development of violence: Common assumptions and controversies. Philos Philos Trans $R$ Soc Lond B Biol Sci. 2008;363(1503):2419-503.

15. Moffitt TE, Lynam D. The neuropsychology of conduct disorder and delinquency: Implications for understanding antisocial behavior. Prog Exp Pers Psychopathol Res, New York, USA. 1994. p.233-262.

16. Moffitt TE. The neuropsychology of conduct disorder. Development and Psychopathology. 1993;5 (1-2):135-151.

17. DeLisi M, Vaughn MG. The Importance Of Neuropsychological Deficits Relating To Self-Control And Temperament To The Prevention Of Serious Antisocial Behavior. International Journal of Child, Youth and Family Studies. 2011;2(1-2):12-35.

18. Ishikawa SS, Raine A. Prefrontal deficits and antisocial behavior: A causal model. In: Lahey et al. (Eds.), Causes of conduct disorder and juvenile delinquency. New York: The Guilford Press, USA. 2003. p. 277-304.

19. Hinshaw SP, Carte ET, Sami N, et al. Preadolescent girls with ADHD: II. Neuropsychological performance in relation to subtypes and individual classification. J Consult Clin Psychol. 2002; 70(5):1099-1111.

20. Clark C, Prior M, Kinsella GJ. Do executive function deficits differentiate between adolescents with ADHD and Oppositional Defiant/ Conduct Disorder? A neuropsychological study using the Six Elements Test and Hayling Sentence Completion Test. J Abnorm Child Psychol. 2000;28(5):403-414.

21. Moffitt TE. Adolescence-limited and life-course-persistent antisocial behavior: A developmental taxonomy. Psychol Rev. 1993;100(4):674-701

22. Loeber R. Development and risk factors of juvenile antisocial behavior and delinquency. Clinical Psychology Review. 1990;10(1):1-41.

23. Verdejo-García A, Lawrence AJ, Clark L. Impulsivity as a vulnerability marker for substance-use disorders: review of findings from high-risk research, problem gamblers and genetic association studies. Neurosci Biobehav Rev. 2008;32(4):777-810.

24. Komarovskaya I, Loper AB, Warren J. The Role of Impulsivity in Antisocial and Violent Behavior and Personality Disorders among Incarcerated Women. Criminal Justice and Behaviour. 2007;34(11):1499-1515.

25. Shaw DS, Gross HE. What we have learned about early childhood and the development of delinquency. The Long View of Crime: A Synthesis of Longitudinal Research, Springer New York, USA. 2008. p. 79-127.

26. Sexton TL, Alexander JF. Functional Family Therapy Clinical Training Manual. Annie E. Casey Foundation. 2004.

27. Henggeler SW, Sheidow AJ. Empirically Supported Family-Based Treatments for Conduct Disorder and Delinquency in Adolescents. $J$ Marital Fam Ther. 2012;38(1):30-58.

28. Celinska K, Susan F, Chia-Cherng C. An Outcome-Based Evaluation of Functional Family Therapy for Youth with Behavioral Problems. Journal of Juvenile Justice. 2013;2(2):23-36.

29. Garrett CJ. Effects of residential treatment of adjudicated delinquents: A meta-analysis. Journal of Research in Crime and Delinquency. 1985;22(4):287-308.

30. Bean JS .The effect of individualized reality therapy on the recidivism rates and locus of control orientation of male juvenile offenders (unpublished Doctoral dissertation). University of Mississippi, Oxford, United States. 1988

31. Shivrattan JL. Social interactional training and incarcerated juvenile delinquents. Canadian Journal of Criminology. 1988;30(2):145-163.

32. Tolan PH, Cromwell RE, Brasswell M. Family therapy with delinquents: A critical review of the literature. Fam Process. 1986;25(4):619-650.
33. Tolan PH, Cromwell RE, Brasswell M. Family therapy with delinquents: A critical review of the literature. Fam Process. 1986;25(4):619-650.

34. Sexton TL, Alexander JF. Functional Family Therapy Clinical Training Manual. Annie E. Casey Foundation. 2004.

35. Gordon DA, Arbuthnot J, Gustafson KE, et al. Home-based behavioralsystems family therapy with disadvantaged juvenile delinquents. The American Journal of Family Therapy. 1988; 16(3): 243-255.

36. Sexton TL, Alexander JF. Functional Family Therapy for Externalizing Disorders in Adolescents. Handbook of Clinical Family Therapy, ed. Lebow J. New Jersey: John Wiley, USA. 2006. p. 550-4131.

37. Henggeler SW, Melton GB, Brondino MJ, et al. Multisystemic treatment with violent and chronic juvenile offenders and their families: The role of treatment fidelity in successful dissemination. J Consult Clin Psychol 1997;65(5):821-833.

38. Sexton T, Turner CW. The effectiveness of functional family therapy for youth with behavioral problems in a community practice setting. J Fam Psychol . 2010;24(3):339-348.

39. Celinska K, Susan F, Chia-Cherng C. An Outcome-Based Evaluation of Functional Family Therapy for Youth with Behavioral Problems. Journal of Juvenile Justice. 2013;2(2):23-36.

40. Robbins MS, Alexander JF, Turner CW. Disrupting defensive family interactions in family therapy with delinquent adolescents. $J$ Fam Psychol. 2000;14(4):688-701.

41. Shoemaker D. Theories of delinquency: An examination of explanations of delinquent behavior. New York: Oxford University Press, USA. 1984.

42. TylerVO, Brown GD. Token reinforcement of academic performance with institutionalized delinquent boys. J Educ Psychol. 1968;59(3):164-168.

43. Spence SH, Marzillier JS. Social skills training with adolescent male offenders: I. Short-term effects. Behaviour Research and Therapy. 1979;17(1):7-16.

44. Ollendick TH, Hersen M. Social skills training for juvenile delinquents. Behav Res Ther. 1979;17(6):547-554.

45. Bean JS. The effect of individualized reality therapy on the recidivism rates and locus of control orientation of male juvenile offenders (unpublished Doctoral dissertation). University of Mississippi, Oxford, United States. 1988.

46. Garrett CJ. Effects of residential treatment of adjudicated delinquents: A meta-analysis. Journal of Research in Crime and Delinquency. 1985;22(2):287-308.

47. Davidson WS, Seidman E. Studies of behavior modification and juvenile delinquency: A review, methodological critique, and social perspective. Psychol Bull. 1974;81(12):998-1011.

48. Jessness CF, Allison FS, McCormic PM, et al. Evaluation of the Effectiveness of Contingency Contracting with Delinquents. Sacramento, CA: California Youth Authority, USA. 1975. p.43.

49. Wolf MM, Phillips EL, Fixson DL. Achievement Place: Phase II (Vol. 1). Rockville, MD: National Institute of Mental Health, Center for Studies of Crime and Delinquency. 1974.

50. Lipsey MW. What do we learn from 400 research studies on the effectiveness of treatment with juvenile delinquents? InWhat Works? Reducing Reoffending, edited by J. McGuire. New York, NY: John Wiley, USA. 1995. p.63-78.

51. Spence SH, Marzillier JS. Social skills training with adolescent male offenders: II. Short-term, long-term and generalized effects. Behav Res Ther. 1981;19(4):349-368.

52. Glick B, Goldstein AP. Aggression replacement training. Journal of Counseling and Development. 1987;65(7):356-362. 
53. Shivrattan JL. Social interactional training and incarcerated juvenile delinquents. Canadian Journal of Criminology. 1988;30(1):145-163.

54. Kirigin KA, Braukmann CJ, Atwater JD, et al. An evaluation of teaching family (Achievement Place) group homes for juvenile offenders. $J$ Appl Behav Anal. 1982;15(1):1-16.

55. Wolf MM, Phillips EL, Fixson DL. Achievement Place: Phase II (Vol 1). Rockville, MD: National Institute of Mental Health, Center for Studies of Crime and Delinquency. 1974.

56. Guerra NG, Slaby RG. Cognitive mediators of aggression in adolescent offenders: 2. Intervention. Developmental Psychology. 1990;26(2): 269-277.

57. Schlicter KJ, Horan JJ. Effects of stress inoculation on the anger and aggression management skills of institutionalized juvenile delinquents. Cognitive Therapy and Research. 1981;5(4):359-365.

58. Ross RR, McKay B. A study of institutional treatment programs. International Journal of Offender Therapy and Comparative Criminology: An Interdisciplinary Journal. 1976;20(2):167-173.

59. Andrews DA, Zinger I, Hoge RD, et al. Does correctional treatment work? A clinically relevant and psychologically informed meta-analysis. Criminology. 1990;28(3):369-404.

60. Auerbach AW. The role of the therapeutic community "Street Prison" in the rehabilitation of youthful offenders. Doctoral dissertation. George Washington University, Washington DC, USA. 1978.

61. Allen-Hagen B. Youth Crime Control Project: A Final Report on an Experimental Alternative to Incarceration of Young Adult Offenders. Department of Corrections: Washington DC, USA. 1975.

62. Gold C, Voracek M, Wigram T. Effects of music therapy for children and adolescents with psychopathology: a meta-analysis. J Child Psychol Psychiatry. 2004;45(6):1054-1063.

63. Tyson EH. Hip hop therapy: An exploratory study of a rap music intervention with at risk and delinquent youth. Journal of Poetry Therapy. 2002;15(3):131-144.

64. Johnson ER. The role of Objective and Concrete Feedback in Self concept Treatment of juvenile Delinquents in Music therapy. J Music Ther. 1981;18(3):137-147.

65. Montello L, Coons EE. Effects of Active Versus Passive Group Music Therapy on Preadolescents with Emotional, Learning, and Behavioural Disorders. J Music Ther. 1998;35(1):49-67.

66. Madsen $\mathrm{CK}$, Madsen $\mathrm{CH}$. Music as a behaviour modification technique with a juvenile delinquent. Journal of Music Therapy. 1968;5(3):72.

67. Sahmey K. A study on factors underlying juvenile delinquency and positive youth development programs. Published dissertation. NIT Rourkela, Rourkela, India. 2013.

68. Poduthase H. Parent-Adolescent Relationship and Juvenile Delinquency In: Kerala, India: A qualitative study. University of Utah, Utah, USA 2012.
69. Pradheepa P, Murlidharan K. Juvenile delinquency - a socioeconomic and family perspective. Soc Welfare. 2005;51(10):9-12.

70. Shukla KS. Juvenile Delinquency in India: Research Trends and Priorities. Indian Journal of Criminology and Criminalistics. 1982;2:103-113

71. Thilagaraj R. Goal Perceptions of Delinquents and Non-Delinquents: A Comparative Study. Indian Journal of Criminology. 1987;2:145-148.

72. Sundar S. How to introduce standards for competent music therapy, education and training in countries where music therapy is in an early stage of development. Voices World Forum Music Ther. 2006;6(2):1.

73. Nizamie SH, Tikka SK. Psychiatry and music. Indian J Psychiatry. 2014;56(2):128-140.

74. Nawalskar RK, Butey PK. Analytical and comparative Study on effect of Indian Classical Music on human body using EEG based signals. International Journal of Modern Engineering Research. 2012;2(5):3289-3291.

75. Deshmukh AD, Sarvaiya AA, Seethalakshmi R, et al. Effect of Indian classical music on quality of sleep in depressed patients: A randomized controlled trial. Nord J Music Ther. 2009;18(1):70-78.

76. Rumball K. The effects of group musical activity on psychiatric patients in India. Voices World Forum Music Ther. 2010.

77. Singh A, Khess CR. Efficacy of adjuvant music therapy in major depressive episode (unpublished dissertation). Ranchi University, Ranchi. 2003.

78. Chakrabarty S, Nizamie SH, Akhtar S. Music therapy in rehabilitation in schizophrenia (unpublished dissertation). Ranchi University, Ranchi. 2003

79. Banerjee M, Nizamie SH, Akhtar S. Effect of music on cognitive dysfunction in chronic schizophrenia patients (unpublished dissertation) Ranchi University, Ranchi. 2003.

80. Sharma M, Jagdev T. Use of Music Therapy for Enhancing Selfesteem among Academically Stressed Adolescents. Pakistan Journal of Psychological Research. 2012;27(1):53-64.

81. Juslin PN, Laukka P. Expression, perception, and induction of musical emotions: A review and a questionnaire study of everyday listening. Journal of New Music Research. 2004;33:217-238.

82. Antonietti A. Why is music effective in rehabilitation? In: Gaggioli A, et al. (Eds.), Advanced Technologies in Neurorehabilitation. Amsterdam: IOS Publisher, Netherlands. 2009. p.179-194.

83. Zuk J, Benjamin C, Kenyon A, et al. Behavioral and neural correlates of executive functioning in musicia ns and non-musicians. Public Library of Science. 2014;9(6):e99868.

84. Saarikallio S, Erkkila J. The role of music in adolescents' mood regulation. Psychology of Music. 2007;35(1):88.

85. National Crime Records Bureau. Crime in India. New Delhi: Ministry of Home Affairs, Government of India, India. 2014 